American Journal of Applied Sciences 6 (4): 646-651, 2009

ISSN 1546-9239

(C) 2009 Science Publications

\title{
Voltage Collapse Risk Associated to Under-Voltage Capacitive Compensation in Electric Power System Operation
}

\author{
${ }^{1}$ Heraldo Silveira Barbuy, ${ }^{1}$ Alexandre Rocco \\ ${ }^{1}$ Luiz Augusto Pereira Fernandes and ${ }^{2}$ Geraldo Caixeta Guimarães, \\ ${ }^{1}$ University of Santa Cecilia, Santos, Brazil \\ ${ }^{2}$ University Federal of Uberlandia, Uberlandia, Brazil
}

\begin{abstract}
Problem statement: In the operation of an Electric Power System (EPS), it has been usual to provide reactive power injection to avoid an under-voltage bus condition. In some situations an adequate voltage profile will not be a guarantee against Voltage Collapses (VCs) that may cause blackouts as seen in many occurrences around the world. The repeatedly injection of reactive power can turn a bus into a characteristic too much capacitive. Under this condition and in the presence of a considerable percentage of the constant power load type, there will be a high risk of a VC. Any of the indices proposed in the literature as VC Proximity Indicators (VCPIs) may alert the operator about the risk. Approach: In order to elucidate the problem stated, simulations were performed using MatLab/SimPowerSystems. It was used a basic example system composed by an infinite-bus feeding, through a large impedance line, a bus load whose power could be increased in ramp manner. It is also included a shunt capacitive compensation at the load bus every time the voltage value reaches $0.9 \mathrm{pu}$. Therefore, the VC risk increase could be shown by means of graphic results and the indications of some VCPIs sensitivity indices (including the new proposed index). Results: The graphics obtained in this study is a contribution to illustrate the voltage collapse risk problem when dealing with adjustments of voltage profile to meet the system requirements. Also, a VCPI sensitivity indicator using apparent load power was tested. The results have shown that all VCPI responses are very similar for a given case and electric system. Conclusion/Recommendations: Any VCPI information can help in the decision stage between either more reactive power injection or load shedding. A routine can also be developed for a supervisory program in order to alert the operator about $\mathrm{VC}$ risks.
\end{abstract}

Key words: Voltage stability, voltage sensitivity indicator, voltage profile, reactive power support

\section{INTRODUCTION}

In 2004 it was published in this journal a study ${ }^{[1]}$ analyzing the procedure to maintain an adequate voltage profile through the connection of shunt capacitor bank into a load bus to avoid an under-voltage condition. In the analysis, the capacitor was included in a Thevenin equivalent circuit that supplies the load bus.

The PV curves for a load growing with constant power factor are well known as shown in chapter 14 of Prabha Kundur book ${ }^{[2]}$. When a constant power factor load growth is under analysis and the capacitor bank is included, there is a jump from a PV curve to another similar by changing the Thevenin impedance and source voltage $\left(\mathrm{Z}_{\mathrm{th}}\right.$ and $\left.\mathrm{E}_{\mathrm{th}}\right)$. Therefore, the maximum active power the load bus can receive $\left(\mathrm{P}_{\max }\right)$ and the voltage in which it happens $\left(\mathrm{V}_{\max P}\right)$ can be analytically calculated $^{[1]}$.
The mentioned study ${ }^{[1]}$ was very interesting, but it did not alert on the $\mathrm{VC}$ risk that can happen even with the load bus voltage within the permitted limits. This fact is emphasized in the present work which also includes VCPIs and discussions about their application.

In most cases, voltage profile monitoring and control of the EPS is associated with the voltage system stability Arunagiri ${ }^{[1]}$.

In EPS operation it is usual to observe the voltages of the load buses, considered as critical ones. When any of those voltages approaches a minimum value, for instance $0.9 \mathrm{pu}$, a corrective action takes place ${ }^{[3,4]}$. This action is often an injection of reactive power at buses with under-voltage conditions, or in their area, which can be performed every time the same situation is noticed. The alternative option that can be adopted is to apply load shedding in the same area, but it is economically worst.

Corresponding Author: Heraldo Silveira Barbuy, Universidade Santa Cecília, Rua Doutor Oswaldo Cruz, 266-CEP 11.045-907, Santos, SP, Brasil 
However, if the recovery of the voltage level is repeatedly done to attend the load increase and there is a considerable percentage of constant power type load, a VC can occur, even without under-voltage limit violation Huang and Taylor ${ }^{[5,6]}$. In order to avoid this, it is required a load shedding when a VCPI points to a potential danger.

When the active power transmission is improved by means of reactive power injection, the EPS can operate too near its limits. It is statistically demonstrated that, in such situation, the probability of a major blackout is increased Carreras ${ }^{[7]}$.

Some sensitivity indices related to the tangent vector $^{[8]}$ are discussed.

Other VCPI option takes into account the maximum active power $P_{\max }$ of each bus with respect to the current active power $\mathrm{P}^{[8]}$. This was the basis of several programs that have been developed, computing the maximum active power loadability of all buses of the grid, for the current system condition, in real-time operation. Also the analysis of contingency scenarios can be dealt with these software ${ }^{[9-13]}$.

Similarly, the loadability can be analyzed taking into account the maximum apparent power Smax of each bus compared with the current apparent power $\mathrm{S}^{[14]}$.

\section{MATERIALS AND METHODS}

Some classical sensitivity indices used as VCPIs and the normalization criteria for their comparison are defined.

The load bus voltage and some VCPIs were analyzed by simulation with the software MatLab SimPowerSystem using a numerical example.

Another VCPI used in the simulations was the indicator $\left(\mathrm{P}_{\max }-\mathrm{P}_{\text {actual }}\right) / \mathrm{P}_{\max }$, where $\mathrm{P}_{\max }$ can be obtained by the continuation method ${ }^{[8,15]}$ or based in the parameters of the Thevenin equivalent circuit of the electric grid, with the shunt capacitor, that is supplying the load bus ${ }^{[1]}$.

General concepts of sensitivity indices: These indices are defined by the ratio of the differential change in a variable to the differential change in other variable. In a general view these variables can be chosen from the following list:

- Load bus voltage

- Load active power at the bus, or in the area, or in all system

- Load reactive power at the bus, or in the area, or in all system
- Load active power at the bus, or in the area, or in all system

- Active power generated in the area, or in all system

- Reactive power generated in the area, or in all system

- Load apparent power at the bus, or in the area (a proposal of this study)

\section{Sensitivity indices considered in this study:}

- The ratio of decremental bus voltage change to the incremental load bus reactive power change ${ }^{[15]}$, that is: $\mathrm{KS} 1=\Delta \mathrm{Vi} / \Delta \mathrm{Qc}_{\mathrm{i}}(1)$

- The ratio of incremental generated reactive power change in the system to the incremental load bus reactive power change ${ }^{[15,16]}$, that is: $\mathrm{KS} 2=\Delta \mathrm{Qg}_{\text {total }} / \Delta \mathrm{Qc}_{\mathrm{i}}(2)$

- The ratio of decremental bus voltage change to the incremental load bus active power change ${ }^{[8]}$, that is: $\mathrm{KS} 3=\Delta \mathrm{Vi} / \Delta \mathrm{Pc}_{\text {total }}$ (3)

- The ratio of decremental bus voltage change to the incremental load bus active power change ${ }^{[8]}$, that is: $\mathrm{KS} 4=\Delta \mathrm{Vi} / \Delta \mathrm{Pg}_{\text {total }}$ (4)

- The ratio of decremental bus voltage change to the incremental load bus apparent power change, that is: $\mathrm{KS} 5=\Delta \mathrm{Vi} / \Delta \mathrm{Sc}_{\mathrm{i}}(5)$

Normalization of sensitivity indices: Each indicator is normalized here by the ratio of the current value to its initial value. Because of this, the initial normalized value of each indicator is always unitary. Moreover, corresponding to KS1 there is the normalized KS1n and so on for the other indicators. The initial indicator values for the example system used in this work are obtained for a low loading situation.

Simulated model: Figure 1 shows the example system, which consists of the Thevenin equivalent source of the portion of an electric grid that feeds a load bus. This constant power type load is supposed to increase in a ramp rate, keeping the same power factor. Therefore, it results to a 2-bus system, which is equivalent to an nbus system at a particular operation condition.

It was considered a radial system with an infinite bus connected to an ideal generator represented by an ideal voltage source as shown in Fig 1. It is supposed that the load bus receives the power flow through many series-connected transmission lines, so that the equivalent line impedance results in a large single value.

For the numerical data of Fig. 1, it was adopted a line impedance of $(0.03+\mathrm{j} 0.60) \mathrm{pu}$ and an ideal voltage source of $1.05 \mathrm{pu}$, both referred to $100 \mathrm{MVA}$ and 138 $\mathrm{kV}$ bases. 


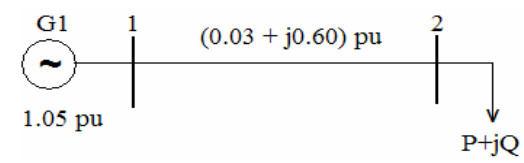

Fig. 1: Example system for simulation

The system configuration used in this paper is similar to the Thevenin equivalent circuit of the IEEE 30 bus model, presented in the reference ${ }^{[1]}$, without the capacitive compensation that is added later and neglecting the shunt capacitance effect of the lines.

All the simplifications aimed the study of the power transmission capability to the load neglecting all the details not necessary for the simulations.

\section{RESULTS}

The first three cases were performed with an aim of testing the performance of the five $\mathrm{VC}$ indices as the system load was increased according to a ramp rate. The results obtained are shown in Fig. 2-4.

In a later simulation, it was included a shunt capacitive compensation at the load bus every time the voltage value reached $0.9 \mathrm{pu}$ (minimum voltage limit considered) because of load increments. The shunt capacitors (constant impedance model) were automatically introduced in sequence as follows: 14.5, $11,8.5,6,5,3.8,3$ and 2.5 MVAr. These reactive power values were calculated to recover the load bus voltage from $0.9 \mathrm{pu}$ to approximately $1.0 \mathrm{pu}$. Using such reactive compensation scheme, the corresponding PV curve of the load bus was drawn and exhibited in Fig. 5.

It must be emphasized that the choice of the bank capacitor values was intended to characterize the jumps from a typical PV curve to another, neglecting the transient disturbance caused in the EPS. The use of a device with continuous adjustment of the reactive power injection should be better in practice but worst for the understanding of the relation of the jumps shown in Fig. 5 and 9 to the change of Thevenin source parameters $Z_{\text {th }}$ and $E_{\text {th }}{ }^{[1]}$.

Although all the sensitivity indicators tested have produced similar results for the simulated example, the indicator KS3 was chosen. This is justified because KS3 has more correlation with the PV curves shown in this study.

VCPI performance for ramp-type load rise with constant power factor: Figure 2 shows the performance of several mentioned sensitivity indices as the load active power is increased, with the inductive power factor kept constant at 0.928 . Notice that just after the active power reaches a value around $61 \mathrm{MW}$, these factors present an abrupt rise.

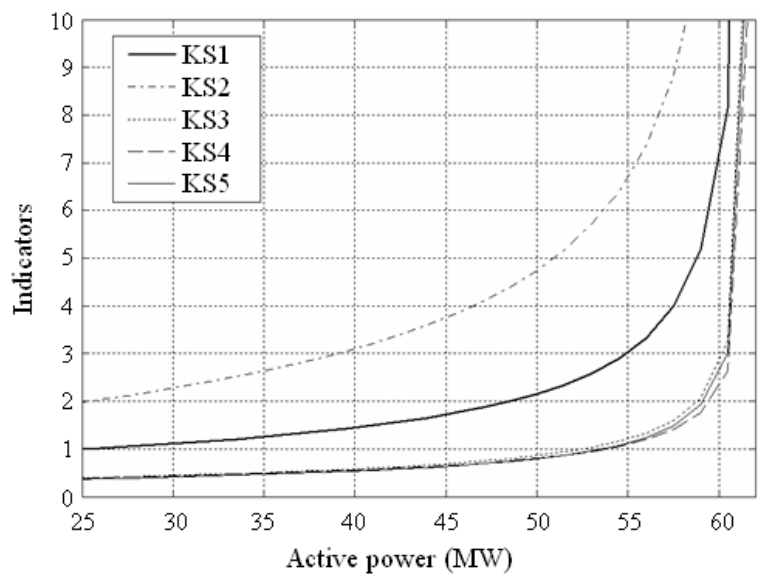

Fig. 2: Sensitivity indicator performances $(f p=0.928)$

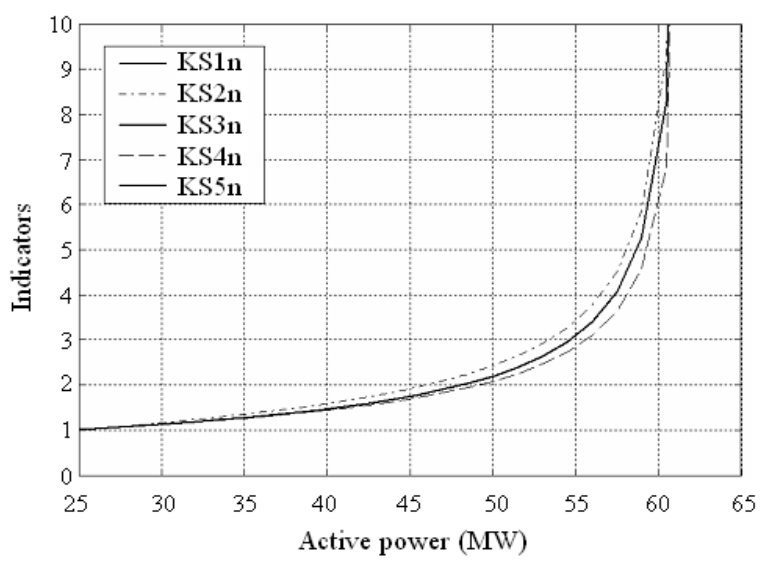

Fig. 3: Normalized sensitivity indicators ( $f \mathrm{p}=0.928)$

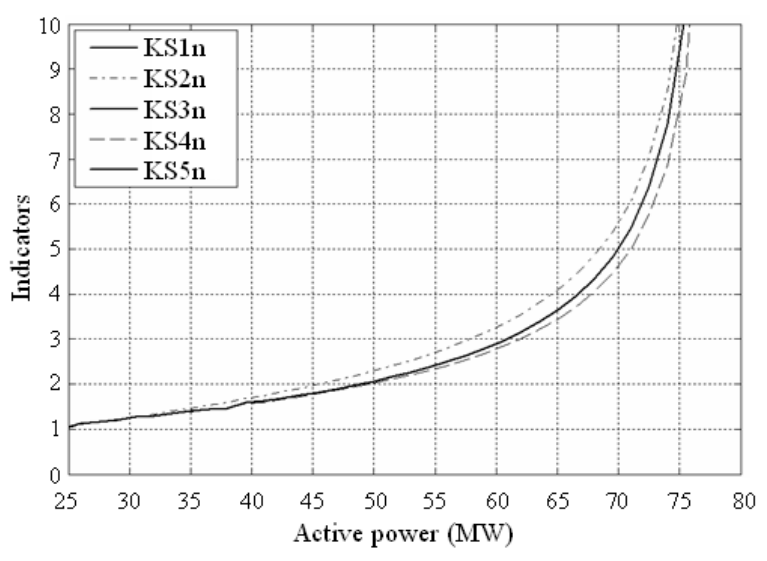

Fig. 4: Normalized sensitivity indicators $(f p=0.99)$

To help the understanding of the behaviors of the indices, Fig. 3 was built to illustrate the same situation of Fig. 2 but now with the sensitivity indicators normalized as mentioned before. 


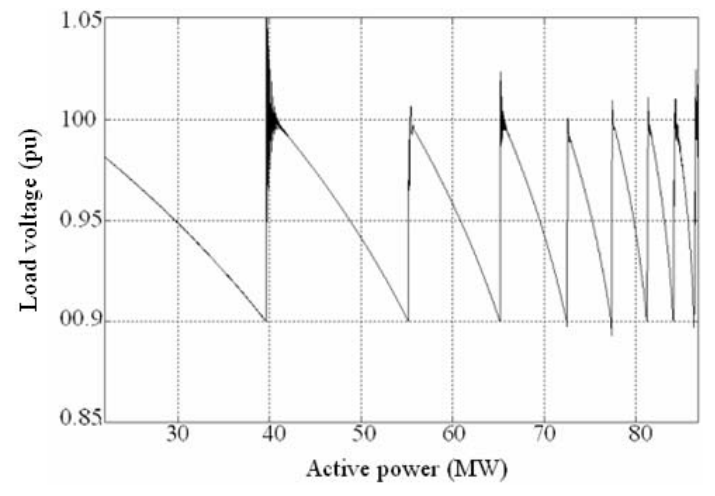

Fig. 5: PV curve with repeated capacitor aggregation

\begin{tabular}{lclll}
\multicolumn{5}{l}{ Table 1: MVAr injection, $\mathrm{P}_{\max }$ and $\mathrm{V}_{\max }$} \\
\hline $\begin{array}{l}\text { Added Qc } \\
\text { (MVAr) }\end{array}$ & $\begin{array}{l}\text { Total Qc } \\
\text { (MVAr) }\end{array}$ & $\begin{array}{l}\mathrm{P}_{\max } \\
(\mathrm{MW})\end{array}$ & $\begin{array}{l}\Delta \mathrm{P}_{\max } \\
(\mathrm{MW})\end{array}$ & $\begin{array}{l}\mathrm{V}_{\operatorname{maxP}} \\
(\mathrm{pu})\end{array}$ \\
\hline 0.0 & 0.0 & 62.20 & 0.00 & 0.6340 \\
14.5 & 14.5 & 67.53 & 5.33 & 0.6883 \\
11.0 & 25.5 & 72.23 & 4.69 & 0.7362 \\
8.5 & 34.0 & 76.33 & 4.10 & 0.7780 \\
6.0 & 40.0 & 79.51 & 3.19 & 0.8104 \\
5.0 & 45.0 & 82.38 & 2.87 & 0.8396 \\
3.8 & 48.8 & 84.70 & 2.32 & 0.8633 \\
3.0 & 51.8 & 86.62 & 1.93 & 0.8829 \\
2.5 & 54.3 & 88.29 & 1.67 & 0.9000 \\
2.0 & 56.3 & 89.68 & 1.39 & 0.9141 \\
1.5 & 57.8 & 90.75 & 1.07 & 0.9250 \\
\hline
\end{tabular}

It must be observed that many power factor values were analyzed but only inductive loads with 0.928 and 0.99 values are presented here.

If the load power factor is 0.99 inductive, the behaviors of the normalized sensitivity indicators change as indicated in Fig. 4. Notice now that the sharp increase in their values will happen later with greater active power load (over $76 \mathrm{MW}$ ).

The graphic curve of the loadability margin is given by $\left(\mathrm{P}_{\mathrm{MAX}}-\mathrm{P}\right) / \mathrm{P}_{\mathrm{MAX}}$ in function of the load active power $(\mathrm{P})$ and it is a straight line decreasing from 1 to 0 when $\mathrm{P}$ grows from 0 to $\mathrm{P}_{\mathrm{MAX}}$.

Voltage profile adjustments: The PV graph shown in Fig. 5 is obtained introducing shunt capacitor in many occasions. The jumps that correspond to the insertion of shunt capacitors can be understood as changes between two PV curves related to changes of Thevenin source parameters $^{[1]}$.

Table 1 shows the maximum active power available $\left(\mathrm{P}_{\max }\right)$ and the corresponding load bus voltage $\left(\mathrm{V}_{\max P}\right)$ related to the capacitive reactive power aggregated (Qc). $\mathrm{P}_{\max }$ and $\mathrm{V}_{\max }$ were calculated using the following Eq. ${ }^{[1]}$ :

$$
P_{\text {max }}=\frac{E^{2} \cos \phi}{2 X\left(1-B_{c} X\right)(1+\sin \phi)}
$$

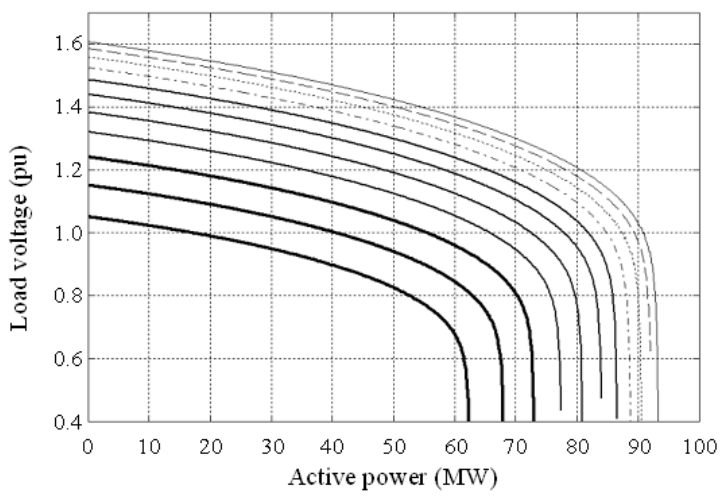

Fig. 6: PV curves for each total MVAr aggregation

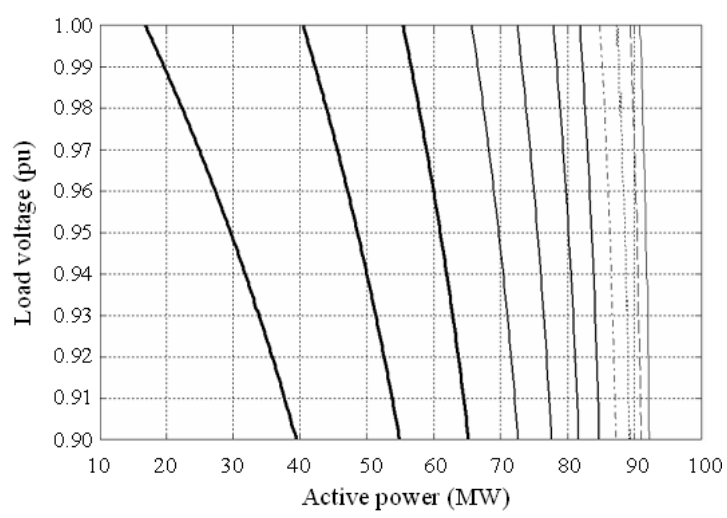

Fig. 7: PV curves detail from 0.9 to 1.0 pu voltage for each total MVAr aggregation

$$
\mathrm{V}_{\max \mathrm{P}}=\frac{\mathrm{E}}{\left(1-\mathrm{B}_{\mathrm{c}} \mathrm{X}\right) \sqrt{2(1+\sin \phi)}}
$$

Figure 6 shows the stable portion of the PV curves for load increases with constant power factor, corresponding to each line of Table 1. In dynamic simulation each curve drops to zero at the end (collapse). In each curve the capacitive impedance aggregated is constant. The lower curve is without capacitive compensation, the next above it is with 14.5 MVAr capacitive aggregation and so on till the upper curve that is with 57.8 MVAr aggregation.

Figure 7 shows in detail the curves of Fig. 6 in the voltage interval from 0.9 to $1.0 \mathrm{pu}$, in order to understand the jumps of Fig. 5 without the dynamical perturbations.

Figure 8 shows the loadability margin straight lines related to each $\mathrm{P}_{\max }$ of table 1 . In each straight line the corresponding capacitive impedance aggregated is constant. 
Am. J. Appl. Sci., 6 (4): 646-651, 2009

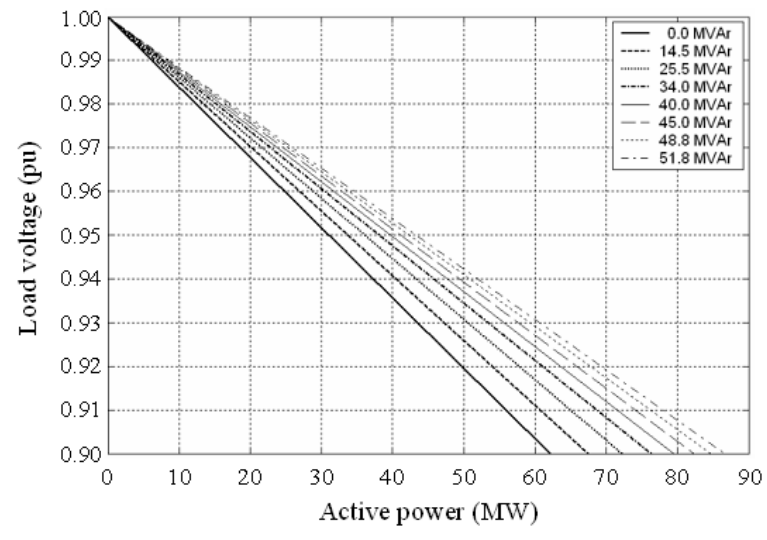

Fig. 8: Loadability margin versus active power, for each total MVAr aggregation
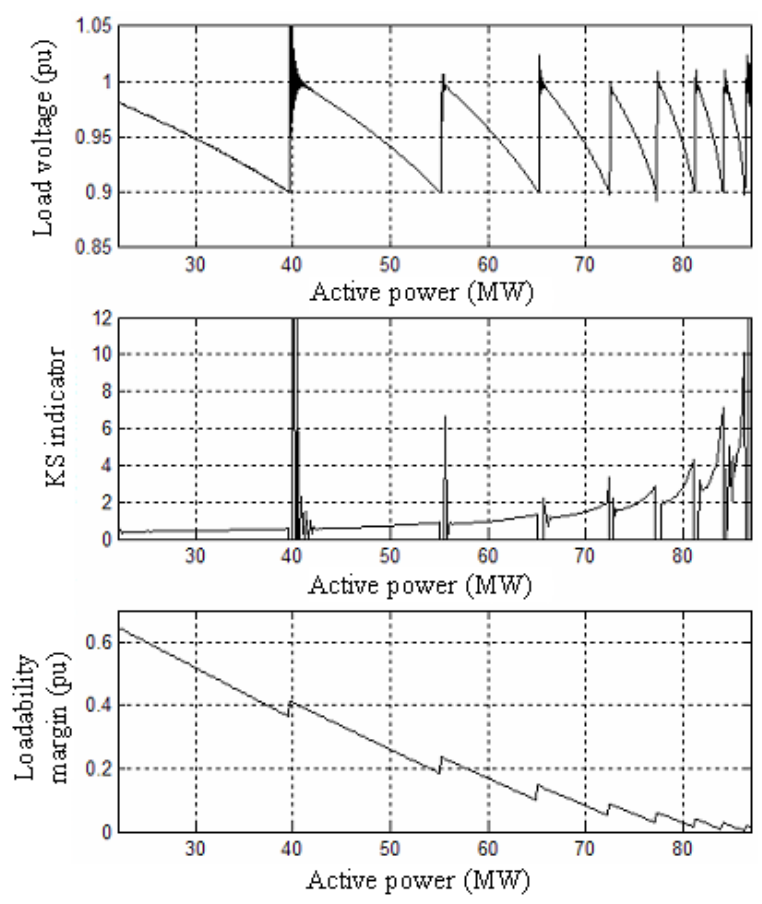

Fig. 9: Loadability margin and KS3 indicator related to the PV curve with repeated MVAr aggregations

As the load power increases and a capacitor bank is added there is a jump from a PV curve to the next above it. A similar jump happens from each loadability margin curve to the above one.

It is observed in Table 1 and Fig. 5-9 that each time the voltage recovery process was repeated, then, the corresponding $\mathrm{P}_{\max }$ increment becomes smaller. In consequence, the loadability margin is not adequately recovered, which leads higher risk of voltage collapse.
Figure 9 shows the KS3 indicator and the loadability margin $\left(\mathrm{P}_{\max } \mathrm{P}_{\text {actual }}\right) / \mathrm{P}_{\max }$ correlated to the PV curve of Fig. 5 (with repeated MVAr aggregations).

\section{DISCUSSION}

Behavior of sensitivity shows Fig. 3 and 4, it is observed a similar behavior for all VCPIs: KS1, KS2, KS3, KS4 and KS5. This is true for any reasonable power factor. The equivalence between the normalized indices KS1n, KS3n and KS5n can be mathematically demonstrated. Using the expressions $\mathrm{KS} 1=\mathrm{KS} 5 \times \cos \varphi$ and $\mathrm{KS} 3=\mathrm{KS} 5 \times \sin \varphi$ and knowing that the load angle $\varphi$ is kept constant during the simulations, then $\mathrm{KS} 1 \mathrm{n}=\mathrm{KS} 3 \mathrm{n}=\mathrm{KS} 5 \mathrm{n}$ because the $\cos \varphi$ and $\sin \varphi$ factors are cancelled in the normalization procedure.

If the bus voltage under analysis depends mainly upon the active and reactive powers supplied to the load at the bus, then it can be used $\mathrm{KS}=\Delta \mathrm{Vi} / \Delta \mathrm{Pc}_{\mathrm{i}}$ (instead of $\left.\mathrm{KS} 3=\Delta \mathrm{Vi} / \Delta \mathrm{Pc}_{\text {total }}\right)$ so that the equivalence mentioned is valid. Otherwise, if the load bus voltage is influenced by the active powers of other busses, then it should be used $\mathrm{KS} 3=\Delta \mathrm{Vi} / \Delta \mathrm{Pc}_{\text {total }}{ }^{[8]}$ and $\mathrm{KS} 1=\Delta \mathrm{Vi} / \Delta \mathrm{Qc}_{\mathrm{i}}$, which yields to $\mathrm{KS} 1 \mathrm{n} \neq \mathrm{KS} 3 \mathrm{n} \neq \mathrm{KS} 5 \mathrm{n}$, in most cases.

Reactive compensation with collapse risk-Fig. 5 and 6: It is shown that repeated reactive power injections to face the continuous load growth can lead the system to VC. This collapse can even happen without a low voltage limit violation. This happens after the last PV curve jump, because the next PV curve collapses with $\mathrm{V}_{\max }=0.90 \mathrm{pu}$. The following $\mathrm{PV}$ curves have respectively $\mathrm{V}_{\operatorname{maxP}}=0.9141 \mathrm{pu}$ and $\mathrm{V}_{\operatorname{maxP}}=0.9250 \mathrm{pu}$. Therefore, voltage collapse happens without voltage limit violation for the three uppermost curves of Fig. 6.

Loadability margin-Fig. 9: It can be recommended a reactive power injection when the voltage becomes low and the loadability margin is greater than a minimum limit $(0.15$, for instance). Otherwise, load shedding is advocated if the voltage becomes low and the loadability margin is smaller than the same limit.

The last capacitor insertions are not adequate to the EPS security, although adequate bus voltages have been obtained. In fact, in such situations the little increment in the power loadability margin results in a condition of unacceptable collapse risk. The VCPI would alert the danger and the correct option should be the load shedding.

KS3 indicator-Fig. 9: When the voltage becomes low and KS3 is smaller than a given minimum limit (1.5 for 
instance), it is suggested to inject reactive power into the load bus. Otherwise, if the voltage becomes low and $\mathrm{KS} 3$ is greater than the same limit it is advisable to perform a load shedding.

\section{CONCLUSION}

The analysis of Fig. 5-9 and Table 1 leads to the following conclusions:

- A new maximum active power ( $\left.\mathrm{P}_{\text {MAXnew }}\right)$ becomes possible as each capacitor bank is inserted. This value corresponds to a new Thevenin source and it is greater than the old maximum active power ( $\left.\mathrm{P}_{\text {MAXold }}\right)$. The difference ( $\left.\mathrm{P}_{\text {MAXnew }}-\mathrm{P}_{\text {MAXold }}\right)$ becomes smaller at each new capacitor bank inclusion. In consequence, in the last stages of capacitor insertions, the improvement of the loadability margin is not enough to obtain a reasonable security

- Voltage level recoveries by means of reactive power injections must be avoided when the loadability margin is too little. In this case, the load shedding is the recommended alternative. The computed loadability margin or any voltage collapse proximity indicator can provide the alert signal to the system operator

\section{REFERENCES}

1. Arunagiri, A. and B. Venkatesh, 2004. Simulation of voltage stability and alleviation through knowledge based system. Am. J. Applied Sci., 1: 354-357. www.scipub.org/fulltext/ajas/ajas14354-357.pdf.

2. Kundur, P., 1994. Power System Stability and Control. 1st Edn., McGraw-Hill, New York, USA., ISBN: 0-07-035958-X, pp: 959-1021.

3. Energy Regulator, 2004. Tasmanian electricity code review of the code for NEM entry, Chapter 8 . www.energyregulator.tas.gov.au/domino/otter.nsf/ LookupFiles/Ch8\%20ministerial.pdf/\$file/Ch8\%20 ministerial.pdf.

4. Aneel, 2001. Resolução n. 505 de 26/11/2001. www.aneel.gov.br/cedoc/res2001505.pdf .

5. Huang, G. and H. Zhang, 2001. Dynamic voltage stability reserve studies for deregulated environment. Proceedings of the Power Engineering Society Summer Meeting, July 15-19, IEEE Computer Society, Washington DC., USA., pp: 301-306. DOI: 10.1109/PESS.2001.970030.
6. Taylor, C.W., 1993, Power System Voltage Stability. 1st Edn., McGraw-Hill, Ohio, USA., ISBN: 0-0706-3184-0.

7. Carreras, B.A., V.E. Lynch, D.E. Newman and I. Dobson, 2003. Blackout mitigation assessment in power transmission systems. Proceeding of the Hawaii Internastional Conference on System Science, Jan. 2003, IEEE Press, USA., pp: 1-10. http://www.pserc.org/ecow/get/publicatio/2002pub lic/carrerashicss03.pdf.

8. Ajjaraju, V. and C. Christy, 1992. The continuation power flow: A tool for steady state voltage stability analysis. IEEE Trans. Power Syst., 7: 416-423. DOI: $10.1109 / 59.141737$.

9. ECI Energy Consulting International, Inc., 2008. QuickStab Software. http://www.eciqs.com.

10. Dynamic Security Assessment Software, 2008. Voltage Security Assessment Tool. http://www.dsatools.com/html/prod_vsat.php.

11. V and R Energy, 2008. V and R Energy Systems Research, Inc. http://www.vrenergy.com/.

12. Bigwood Systems, Inc., 2009. World-class tools for advances power grid analysis and control. http://www.bigwood-systems.com/.

13. Feijó, W.L., F.A.B. Lemos, A.V.Z. Zampieri and A.L. Franceschi, 2003. Real time voltage control actions simulation and monitoring system. http://66.102.1.104/scholar?hl=en\&lr=\&q=cache:e 9_x9RZ52pEJ:citenel.aneel.gov.br/historico/IIciten $\mathrm{e} \overline{\mathrm{l}} /$ Anais $\% 2520 \mathrm{do} \% 2520 \mathrm{II} \% 2520 \mathrm{Citenel} \% 2520$ $\% 2520$ VOLUME\%2520II/Supervisao_Controle_e Automacao_de_Sistemas.pdf.

14. Prada, R.B., E.G.C.C. Palomino, J.O.R. dos Santos, A. Bianco and L.A.S. Pilotto, 2002. Voltage stability assessment for real-time operation. Proc. IEE Generat. Transmiss. Distribut., 149: 175-181. DOI: $10.1049 / 20020282$.

15. Begovic, M.M. and A.G. Phadke, 1992. Control of voltage stability using sensitivity analysis. IEEE Trans. Power Syst., 7: 114-123. DOI: 10.1109/59.141694.

16. Lemaître, C., J.P. Paul, J.M. Tesseron, Y. Harmand and Y.S. Zhao, 1990. An indicator of the risk of voltage profile instability for real-time control applications. IEEE Trans. Power Syst., 5: 154-161. DOI: $10.1109 / 59.49100$. 